\title{
Burnout In Orthopaedic and Trauma Surgeons of Nepal
}

\author{
Dipendra Maharjan, Ritesh Sinha, Rajesh Pratap Shah, Sushil Rana Magar \\ Department of Orthopaedics, Shree Birendra Hospital, Kathmandu, Nepal
}

Correspondence: Dr. Dipendra Maharjan; Email: ptosis@gmail.com Contact No.: 9841453743

\begin{abstract}
Background: Burnout is a syndrome, which consists of detachment from patients and colleagues, emotional tiredness and lack of achievements in personal life. Freudenberger HJ coined the term "burnout" in the 1970s and categorized in three categories namely depersonalization, emotional exhaustion and personal achievement. Since then there has been a lot of research on the effects of stress, work or emotion, on behavior and in professional life. Surgeons are particularly exposed to burnout and more common than in the general population and have been found that the burnout in orthopaedic surgeon is more than in any other specialty. There is a high level of dissatisfaction in orthopaedic surgeons in Nepal, who are emotionally harassed and tired of lack of achievements. There were research on burnout and over orthopaedic surgeon in different countries but there was no research on burnout and no studies were conducted in orthopaedic surgeons of Nepal. Therefore, this study was conducted to evaluate the burnout level of orthopaedic surgeons of Nepal.
\end{abstract}

Methods: An observational transverse contacted survey among Nepalese orthopaedic and trauma surgeon by voluntary sample technique was conducted in Kathmandu Nepal between September 2018 - August 2019; using a self-administered questionnaire in digital as well as printed form that was based on the Maslach Burnout Inventory. Demographic and occupational data were also collected.

Results: Out of all contacted surgeons, 34 responded. The mean age was 35 and all were male. Almost everyone showed a high level of emotional exhaustion (94\%), depersonalization (100\%) and only 32\% showed a high level of personal achievement.

Conclusion: Burnout syndrome is consisting of depersonalization, emotional exhaustion and personal achievements and showed frightening level of emotional exhaustion, depersonalization and a satisfactory level of personal achievements.

Keywords: Orthopaedic surgeon, burnout, depersonalization, emotional exhaustion, personal achievement, trauma surgeon, Maslach Burnout Inventory

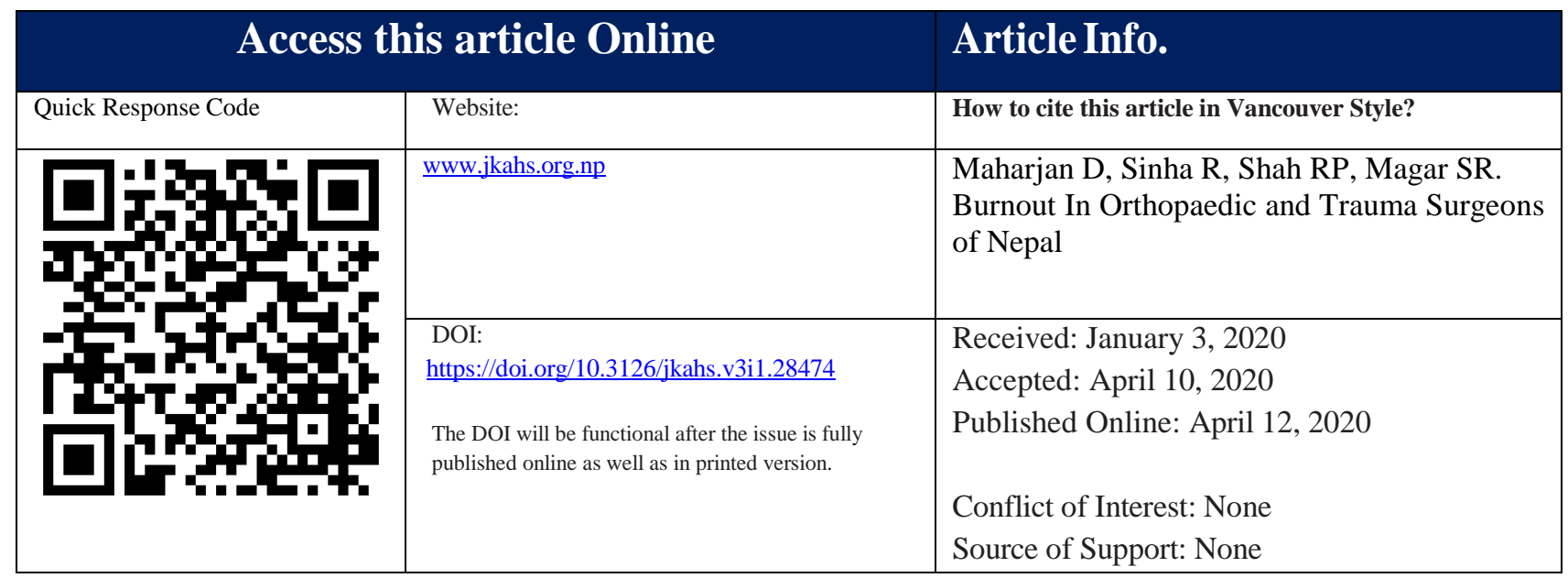




\section{INTRODUCTION}

Burnout is a syndrome, which consists of detachment from patients and colleagues (depersonalization), emotional tiredness and lack of personal achievements. ${ }^{1}$

Freudenberger HJ coined the term "burnout" in the 1970s. ${ }^{2}$ The burnout was categorized into three main section; emotional exhaustion, depersonalization and personal achievement. Emotional exhaustion focused on poor judgment, cynicism, emotionally detachment where as depersonalization is focused on guilt, feelings of ineffectiveness and sense of depersonalization in relationships with coworkers and patients. Personal achievement denotes sense of competence and accomplishments. There has been a lot of research on the effects of stress, work or emotion, on behavior and in professional life. ${ }^{3}$

The medical profession is one of the most stressful and demanding professions. ${ }^{4}$ Medical profession is high demanding which consists of long hour work, physical exhaustion and mental stress regarding patients and its outcome. This leads to tiredness, poor judgement, decrease sense of competence, lack of sense of achievements. That's why, there has been studies done in medical profession regarding burnout and showed that the burnout rate over medical profession has been the most. ${ }^{5}$ The research targeting the surgeons and physicians showed that it was higher among the medical personnel than in the general workers. ${ }^{4-8}$ In one of few studies done over orthopaedic surgeons, it has been found that the orthopaedic surgeons experienced the symptoms of burnout more in comparison with other medical field. ${ }^{9}$ and showed a burnout rate of $40 \%$ to $60 \%$. $^{10-12}$

The research done over medical profession showed the symptoms of burnout, which lead to have decreased in quality of care leading to medical errors as well as depersonalization. These study concluded that the burnout infected orthopaedic surgeons the most among other medical profession with high level of depersonalization and lower level of personal achievements. This corresponds with other general surgeons in emotional exhaustion and depersonalization. Therefore, it has been concluded in several studies that surgeons were particularly exposed to burnout, orthopaedic surgeons mainly. ${ }^{13}$

Nepal is a small country and there are an increasing number of orthopaedic surgeons in Nepal. With the increasing demand, more working hours, proper care and repeated manhandling of medical professionals, and cross-checking doctors for malpractice, surgeons are particularly exposed to burnout. ${ }^{14}$ It is becoming very difficult to counsel a patient regarding appropriate treatment, and the workload for the self- 
fulfillment is very high. All these reasons lead to dissatisfaction in personal life, and a poor quality of life in a personal level of a medical person. ${ }^{15}$ There were researches on burnout over orthopaedic surgeon in different country but there is no research on this matter in our country and there have been no studies in orthopaedic surgeons. We assume that orthopaedic surgeons of Nepal are highly infected with burnout syndrome. Therefore, we conducted this study to evaluate the burnout level of orthopaedic surgeons of Nepal.

\section{MATERIALS AND METHODS}

\section{Study population}

An observational transverse survey contacted Nepalese orthopaedic and trauma surgeons based at Kathmandu. Nepal Medical Council certified all the participants as an orthopaedic and trauma surgeons had been accepted for the survey. The survey sample was based upon voluntary sample technique. The candidates were contacted directly or via email. The survey was approved by Institutional Review Board of Nepal Army Institute of Health Science approved the survey and data collection was started. All the orthopaedic surgeons certified by Nepal Medical Council have been accepted for the survey.

\section{Data collection}

The self-administered questionnaire was uploaded in Google form and the link was emailed to 50 orthopaedic and trauma surgeons. $45 \%$ were false or out of date, leaving 27. Data were collected between September 2018 and August 2019. The email consisted of a request to respond, explanations about the study and a link to the online survey form. The online survey form consisted of an example to teach how to fill the form. Orthopaedic surgeons were contacted directly in events like continuous medical education, and seminars with a request to fill the form in person who did not respond via Google form. All of orthopaedic surgeons contacted directly, only 7 agreed to participate. The participation was voluntary and data were kept anonymous. The consent was taken prior to fill the form.

\section{Assessment methods}

Burnout was assessed on the basis of the Maslach Burnout Inventory 2, a validated 22item questionnaire widely used in the literature. ${ }^{15}$ It includes three fields of burnout on three scales. A high score in one field is considered to be positive for burnout with pathological score on 2 or 3 scale. Additional scores confirm the severity of burnout.

\section{Statistics}

The analysis was done using SPSS software version 23. The descriptive analysis was conducted as mean for age, sex, number of years of experience as an orthopaedic surgeon, and number of patients or surgeries in a week. Beside descriptive analysis, we analyzed the categories of burnout separately 
as emotional exhaustion, depersonalization and personal achievement.

\section{RESULTS}

In total, 34 orthopaedic and trauma surgeons responded the request. The mean age was 38 with standard deviation of 6.61 and all were male. The range of age was 28 to 63 years old. The average number of outpatient department (OPD) is 3.6 days per week with standard deviation of 1.77; average number of surgery was 3 per week with standard deviation of 7.31; average number of patient per day was 32.7 with standard deviation 14.20; average number of ssurgery was 9.9 per week with standard deviation 5.70. Most of the orthopaedic surgeons were affiliated to teaching institute and government hospitals. In this study, there were few orthopaedic surgeons who had 0 patients per day, 0 surgeries per week and those were planning to go abroad for their further studies.

Table showing the frequencies of age; number of OPD per week; operations per week, number of patients in OPD and number of surgeries done in a week.

\begin{tabular}{|c|c|c|c|c|c|c|}
\hline & Age & $\begin{array}{l}\text { No. of years as an } \\
\text { orthopaedic } \\
\text { surgeons }\end{array}$ & $\begin{array}{l}\text { No. of OPD } \\
\text { in a week }\end{array}$ & $\begin{array}{lr}\begin{array}{l}\text { No. } \\
\text { operation }\end{array} & \text { of } \\
\text { in a week }\end{array}$ & $\begin{array}{l}\text { Average no. of } \\
\text { patients in a day }\end{array}$ & $\begin{array}{l}\text { Av. No. of } \\
\text { surgery in } \\
\text { a week }\end{array}$ \\
\hline Mean & 38 & 5.5 & 3.6 & 3 & 32.7 & 9.9 \\
\hline Minimum & 28 & 1 & 0 & 0 & 0 & 0 \\
\hline Maximim & 63 & 26 & 6 & 5 & 60 & 20 \\
\hline
\end{tabular}

The result of personal achievement is comparatively good among other factors of burnout syndrome. The result showed 32\% (11) had high degree of personal achievement, $38 \%$ (13) had moderate level of personal achievement and 30\% did not felt any achievement as shown in figure 1.

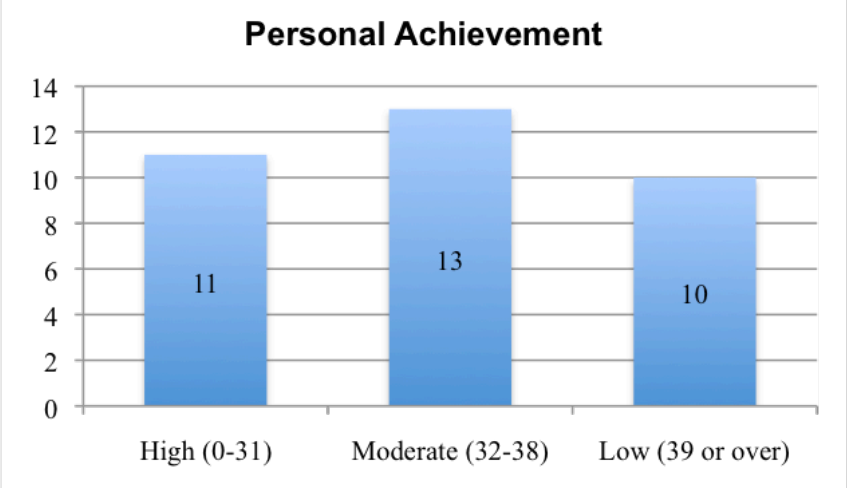

The emotional exhaustion as shown in figure 2 was extremely high, 94\% (32) showed high level of exhaustion.

Figure 1: Bar diagram showing personal achievement 


\section{Depersonalization}

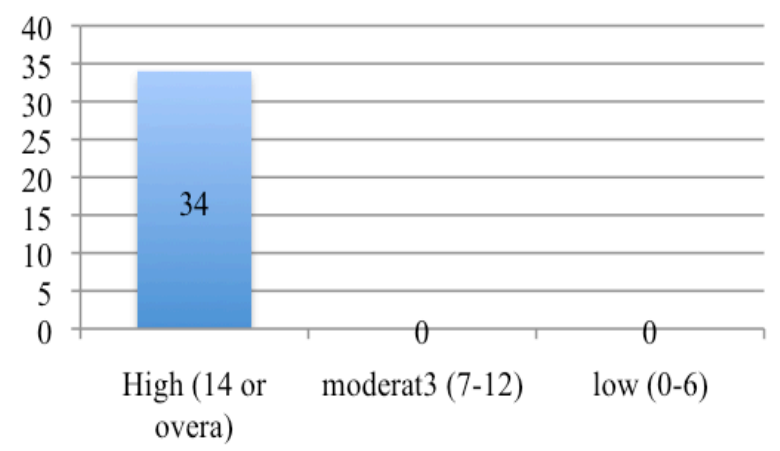

Figure 3: Bar diagram showing the depersonalization

If we see the figure 3 , there is complete depersonalization among orthopaedic surgeons, $100 \%$ (34) result was seen.

\section{DISCUSSION}

Burnout is diagnosed if there is presence of two or more than two positive category. Those categories of burnout include emotional exhaustion, depersonalization and personal achievement. This study was an approach to understand the burnout level of Nepalese orthopaedic and trauma surgeons who were certified by Nepal medical council for practice. The results achieved in our study are the current scenario of burnout in orthopaedic and trauma surgeons.

The result showed good amount of orthopaedic surgeons feels satisfaction regarding personal achievement as in figure 1. This probably due to presence of young orthopaedic surgeons who enjoyed or satisfied doing new procedure during surgeries and trying to achieve approaches or new method to do orthopaedic surgeries and the amount of money they receive after completing the surgery. There is wide area in orthopaedics that can be explored which is interesting and attractive for new orthopaedic and trauma surgeon and does fellowship in their choice of sub-speciality. Probably, Being able to do what one loves to do might be the reason that they are satisfied with their personal achievement. Some might have done surgery they have been dreaming of. These might be the reasons for a high level of personal achievement in $43 \%$ of the orthopaedic surgeons in out study.

The emotional exhaustion demonstrates the level of physical and mental exhaustion, poor understanding of patient, difficult to communicate with patient party, long hours to work and need to work for financial benefit, lack of rest, poor judgement, medical error. The level of emotional exhaustion in this study was very high, approximately $94 \%$ as shown in figure 2. The foremost reason for emotional exhaustion might be difficulty in getting job. Then, there is a need to satisfy the seniors to have some exposure or to do the surgery one wants. There is also patient factor, which do not understand the explanation of disease or the procedure to be performed. Beside all these, everyone has their personal life and the imbalance between their professional and personal life is very exhausting. 
The personal detachment is another category in burnout. This shows emotional detached from patient and with self, lack of empathy, lack of sympathy, irresponsibility and inability to attach to emotion. There is imbalance between professional life and social as well as personal life. The career once charming, turned into unrewarding with lack of improvement and guidance, lack of autonomy and personal decision while working in an institute. This study showed, as in figure 3, the high level of depersonalization among orthopaedic and trauma surgeons of Nepal. The main reason behind this might be the need to work long hours, and visit different clinics or hospitals to earn sufficient money. The stressful life and relationship with patients and their families, along with their unnecessary demands regarding treatment, also contribute as a reason for depersonalization. There is decreased quality of life with families because of long working hours and getting tired when coming home.

The third category is personal achievement. In studies done by Cozens and Barden, The researchers noted that the surgeons or physicians were infected with at least one of the symptoms of burnout. These symptoms have shown decrease in quality of surgeons and patient care leading to the medical errors and to the worst, depersonalization. ${ }^{16,17}$ If we compare this study with current study, the level of burnout is comparable and extremely high in current study as well. With this result, we cannot stop thinking about medical error that might be happening or that there is high chance of occurring medical error in every operation that orthopaedic surgeons are doing as we found that there is high level of burnout in participated orthopaedic surgeons.

The study conducted by Lesi and team found out that orthopaedic surgeons showed higher rate of depersonalization and lower rate of personal achievement. ${ }^{18}$ The study that we did is similar with the study of Lesi, there is higher rate of depersonalization, emotional exhaustion and moderate level of personal achievement.

The study done by Sadat Ali concluded that it has been found that the high levels of emotional exhaustion and depersonalization marked the burnout in surgeons, whereas feelings of personal achievement were often preserved in comparison with other field of medicine. The results were matching with the current study. ${ }^{19}$ The result showed high level of emotional exhaustion and depersonalization with preservation of personal achievement in this study as well. The results of this study showed high level of burnout in Nepalese orthopaedic and trauma surgeons though few people agreed to join and some did not agree regarding uncovering of there current status. They did not want to expose their number of OPDs, surgeries, 
number of patients they treat everyday. During this study, few orthopaedic surgeons were reluctant to participate. Some denied strongly, some participated with a request that the results will be anonymous. To those who participated after full consent, few filled the form without reading thoroughly even when they were requested. Some did with seriousness, as they were happy to participate in a research that had been an attempt to understand the level of burnout. This limited the participation of orthopaedic surgeons in this study. They were afraid to be diagnosed as burnout with emotional exhaustion or depersonalization or less personal achievement.

In this study, there were mostly young orhtopaedic surgeons. The emotional exhaustion and depersonalization level of burnout showed mostly in young orthopaedic and trauma surgeons. The result revealed that senior orthopaedic and trauma surgeons were less emotionally exhausted, had high level of personal achievements and negligible level of depersonalization. The number of senior orthopaedic surgeon were less, however, this showed that they had achieved what they wanted in their life, they had time to spend with family and they could overcome stress in their daily life. They were stable in every field like earning money, having personal time, time for family, ability to counsel patient, overcome any complications
However, the burnout level was not compared with any other profession in this study.

\section{Limitations}

Although the study showed disastrous result, the study had methodological limitations. There was scarce of participation from registered orthopaedic and trauma surgeons. Their unwillingness and hesitation lead to the small number of participation. The study did not investigated the exact cause of high level of burnout at this point, but this need to be done in national level with an interest to pinpoint the cause of burnout.

\section{CONCLUSION}

The survey concludes that the burnout was highly present in orthopaedic and trauma surgeons. It showed high level of emotional exhaustion, depersonalization with moderate level of personal achievement. Even though the survey suggested significant level of burnout in participated orthopaedic and trauma surgeons, we were unable to conclude the same result among all certified orthopaedic surgeon. Hence, a national level survey should be conducted to find the exact scenario of burnout among orthopaedic and trauma surgeons. 


\section{REFERENCES}

1. Maslach C. Schaufeli WB, Leiter MP. Job burnout. annu Rev Psychol. 2001;52:397-422.doi; 10.1146/annurev.psych.52.1.397.

Google Scholar | PubMed | Full Text

2. Freudenberger HJ. Burnout: Past, present, and future concerns. Loss, Grief \& Care. 1989 Feb 15;3(1-2):1-0. Google Scholar

3. Daniels AH, DePasse JM, Kamal RN. Orthopaedic surgeon burnout: Diagnosis, treatment, and prevention. JAAOS-Journal of the American Academy of Orthopaedic Surgeons. 2016 Apr 1;24(4):213-9.doi: 10.5435/JAAOS-D-15-00148.

Google Scholar | Full Text

4. Shanafelt TD, Balch CM, Bechamps GJ et al: Burnout and career satisfaction among American surgeons. Ann Surg 2009;250(3):463-71.

Google Scholar | Full Text.

5. Arora M, Diwan AD, Harris IA. Burnout in orthopaedic surgeons: a review. ANZ journal of surgery. 2013 Jul;83(7-8):512-5.

$\underline{\text { Google Scholar | PubMed | Full Text }}$

6. Vijendren, A., Yung, M. \& Sanchez, J. The ill surgeon: a review of common work-related health problems amongst UK surgeons. Langenbecks Arch Surg 399, 2014;967-979.

Google Scholar | Full Text

7. Golub JS, Johns MM III, Weiss PS, Ramesh AK, Ossoff RH Burnout in academic faculty of otolaryngology-head and neck surgery. Laryngoscope 2008;118(11):1951-6.

$\underline{\text { Google Scholar } \mid \text { Full Text }}$

8. Gabbe SG, Melville J, Mandel L, Walker E Burnout in chairs of obstetrics and gynecology: Diagnosis, treatment, and prevention. Am J Obstet Gynecol 2002;186(4):601-12.

Google Scholar $\mid \underline{\text { CrossRef }}$

9. Shanafelt TD, Boone S, Tan L, et al Burnout and satisfaction with work-life balance among US physicians relative to the general US population. Arch Intern Med 2012;172(18):1377-85.

$\underline{\text { Google Scholar | PubMed | CrossRef }}$

10. Arora $M$, Diwan AD, Harris IA Burnout in orthopaedic surgeons: A review. ANZ J Surg 2013;83(7-8):512-15. $\underline{\text { Google Scholar | PubMed | CrossRef }}$

11.Sargent MC, Sotile W, Sotile MO, Rubash H, Barrack RL Quality of life during orthopaedic training and academic practice: Part 1. Orthopaedic surgery residents and faculty. J Bone Joint Surg Am 2009;91(10):2395-2405. Google Scholar | CrossRef

12.Saleh KJ, Quick JC, Sime WE, Novicoff WM, Einhorn TA Recognizing and preventing burnout among orthopaedic leaders. Clin Orthop Relat Res 2009;467(2):558-65.

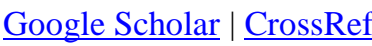

13. Dimou FM, Eckelbarger D, Riall TS. Surgeon burnout: a systematic review. Journal of the American College of Surgeons. 2016 Jun;222(6):1230.

Google Scholar | CrossRef

14. Campbell Jr DA, Sonnad SS, Eckhauser FE, Campbell KK, Greenfield LJ. Burnout among American surgeons. Surgery. 2001 Oct 1;130(4):696705. Google Scholar

15. Dyrbye LN, Shanafelt TD, Balch CM, Satele D, Sloan J, Freischlag J. Relationship between work-home conflicts and burnout among American surgeons: a comparison by sex. Archives of surgery. 2011; 1;146(2):211-7. Full Text

16. Firth-Cozens J, Greenhalgh J Doctors’ perceptions of the links between stress and lowered clinical care. Soc Sci Med 1997;44 (7):1017-22.

Google Scholar | CrossRef

17. Barden CB, Specht MC, McCarter MD, Daly JM, Fahey TJ III Effects of limited work hours on surgical training. J Am Coll Surg 2002;195(4):531-38.

Google Scholar | PubMed | CrossRef

18. Lesi c AR, Stefanovic NP, Perunici c I, Milenkovi c P, Tosevski DL, Bumbasirevi c MZ Burnout in Belgrade orthopaedic surgeons and general practitioners: A preliminary report. Acta Chir Iugosl 2009;56(2):53-59.

Google Scholar | CrossRef | Full Text

19. Sadat-Ali M, Al-Habdan IM, Al- Dakheel DA, Shriyan D Are orthopedic surgeons prone to burnout? Saudi Med J 2005;26(8):1180-82. PMID: 16127509 Google Scholar 